\title{
Investigating Web Based Marketing in the Context of Micro and Small-Scale Enterprises (MSEs): A Decision Tree Classification Technique
}

\author{
Monica N. Agu \\ University of Nigeria, Nsukka, Nigeria \\ monica.agu@unn.edu.ng
}

Stephen Nabareseh and Christian N. Osakwe

Tomas Bata University in Zlin, FAME, Zlin, Czech Republic

nabareseh@fame.utb.cz osakwe@fame.utb.cz

\begin{abstract}
This paper presents the findings of an exploratory study of web based marketing (WBM) usage predictor variables in the context of micro and small-scale enterprises (MSEs). By means of a cross-sectional field study, a structured questionnaire was used to elicit responses from 267 enterprises situated in the South East Region of Nigeria. The main rationale for this study is to provide a vivid description of pertinent variables that are most likely to influence an enterprise's consideration of the relevance and/or implementation of WBM. Against this backdrop, the authors used the decision tree classification technique of data mining to build a predictive model. One of the interesting findings in this study seems to show that service-oriented enterprises that have a social media presence and are equally headed by highly educated women have a higher proclivity of engaging in WBM. By and large, our findings provide an understanding of idiosyncratic factors that impact on WBM non (usage) by enterprises. Lastly, our findings have implications for practitioners and policy makers in developing countries, particularly that of Nigeria.
\end{abstract}

Keywords: decision tree classification technique, developing country, Internet, micro and smallscale enterprises (MSEs), Nigeria, social media, web based marketing (WBM).

\section{Introduction}

Micro and small-scale enterprises (hereafter referred to as "MSEs") are widely heralded as the economic hope of most developing economies of the world given that MSEs contribute immense-

Material published as part of this publication, either on-line or in print, is copyrighted by the Informing Science Institute. Permission to make digital or paper copy of part or all of these works for personal or classroom use is granted without fee provided that the copies are not made or distributed for profit or commercial advantage AND that copies 1) bear this notice in full and 2) give the full citation on the first page. It is permissible to abstract these works so long as credit is given. To copy in all other cases or to republish or to post on a server or to redistribute to lists requires specific permission and payment of a fee. Contact Publisher@InformingScience.org to request redistribution permission. ly to the economic prosperity of the developing world (Centeno, 2001; Coad \& Tamvada, 2008; Eshetu, Ketema and Kassa, 2013; McPherson, 1996; Mead \& Liedholm, 1998; Woldeyohanes, 2014). However, numerous studies (e.g., Daniels, 1999; Fajnzylber, Maloney \& Montes-Rojas, 2009; Hampel-Milagrosa, Loewe \& Reeg, 2015; Nichter \& Goldmark, 2009) posit that MSEs are indeed struggling to fulfil their econom- 
ic potentials in the developing world owing to the fact that they are constantly confronted with a myriad of challenges such as lack of slack resources, limited access to finance, lack of skilled manpower, and limited marketing with technological expertise.

Against this backdrop, we argue that for MSEs to possibly realize their market potentials in our contemporary world, they would have to come to terms with the forces of globalization and most notably catch up with the fast pace of Internetization (Abouzeedan, Klofsten \& Hedner, 2013; Etemad, Wilkinson \& Dana, 2010). Recently, it has begun to dawn on MSEs in developing societies that they could as well leverage on online platforms to conduct seamless business transactions with their end-consumers given the rise of online shopping malls (such as Alibaba in China, Lazada in South East Asia, MercadoLibre in Latin America, GTBank SME MarketHub in Nigeria, etc.) in some of these developing countries. In today's competitive business landscape, it behoves on firms irrespective of size and location, to tap into the huge potentials of the electronic marketplace. Hence, web based marketing serves as a strategic lever for any enterprise that seeks to gain global market appeal, increase its customer relationship performance metrics and overall market potentials, as well as its visibility in the marketplace (Bengtsson, Boter \& Vanyushyn, 2007; Trainor, Rapp, Beitelspacher \& Schwillewaert, 2011; Tsiotsou \& Vlachopoulou, 2011; Varadarajan \& Yadav, 2002).

Consequently, web based marketing within the confines of this study includes the usage of Internet-based platforms (e.g., emails, corporate websites, social media sites, third-party eMalls, etc.) to promote enterprises' product/service offerings, build brand image, and ultimately to build and strengthen an enterprise's relationship with relevant stakeholders (most notably potential/existing customers with suppliers). In addition, web based marketing might equally entail the capacity of an enterprise to sell its products directly to consumers through the aforementioned Internet platforms. In such an instance, it may involve either cash or non-cash based electronic transactions. However, the scope of the present study does not take into cognizance sophisticated Internet marketing tools such as search engine optimization (SEO), search engine marketing (SEM), and location-based service (LBS) given that a majority of MSEs operating in developing countries hardly make use of these sophisticated tools.

Despite the limitless marketing opportunities inherent in the online marketplace, we would like to stress that due to limited Internet infrastructure and its attendant effect of higher service charge for Internet subscription in most of the developing countries and more specifically that of Nigeria; web based marketing (WBM) may appear as a luxury for MSEs rather than a necessity. More so, as earlier highlighted, a majority of MSEs in the developing world, and particularly that of Nigeria are often confronted with all sorts of contextual issues (e.g., technological, organizational, and environmental factors- Tornatzky \& Fleischer, 1990) especially when it comes to the usage of an innovative marketing technology, particularly that of, WBM.

Most importantly, the main rationale for this paper is to provide a more vivid description of variables that may possibly impact on whether or not an enterprise considers the implementation of WBM as a necessary strategic marketing lever for achieving a competitive edge in the marketplace. In the light of the above, this study seeks to address some of the contextual relevant factors that are most likely responsible for the (non) usage of WBM by MSEs that are situated in one of the economic powerhouses of the African continent. More specifically, this study seeks to answer the following research questions:

* What is the current adoption level of WBM among the surveyed MSBs in Nigeria?

* How relevant is WBM for MSEs operating in Nigeria?

* What relevant factors necessitate the usage of WBM by MSEs operating in Nigeria?

* What is/are the main predictor variable(s) to predict whether MSEs are currently using WBM? 
In order to achieve our primary objective in this study and coupled with the fact that our research is primarily descriptive and exploratory in nature, the decision tree classification technique of data-mining approach is used. The basis for using a decision tree analysis is to ascertain the various kinds of relationships that may possibly exist in our sample data. Put differently, we have opted for the use of decision tree since we are actually interested in predicting probable factors that are responsible for the usage of WBM among the aforementioned enterprises. More so, we believe we could learn more from the dataset by using decision tree as the predictive model taking into account that a decision tree is a form of multiple effect analysis that is capable of handling various levels of data measurement (SAS Support, n.d., p. 8). By and large, we believe that by using the decision tree model in this study, we could possibly arrive at new and important findings. This is arguably the first study in a Sub-Saharan African country that would be using this particular technique in the context of firm-level data, particularly MSEs.

Decision tree classification is a process used to partition data into units of smaller divisions on the basis of nodes and leaves (Quinlan, 1987). The nodes serve as predictors to the variable to be predicted and the leaves describe the portions of the variables that are aligned to the predicted variable. Decision trees serve as a decision tool in a tree-like manner or in the form of a flowchart of decisions with events and likely outcomes based on probabilities. More so, decision tree has been proven to be more robust than regression analysis given that it is more efficient in handling missing data, non-parametric data and together with its ease of comprehensibility, which is often times aided by means of graphical illustration(s) (Chen, 2009; SAS Support, n.d.).

In sum, we expect that the findings of the study will provide further insights on the (non) usage of WBM by MSEs in the developing world, especially in the Nigerian context. Therefore, the findings will add to our understanding of the idiosyncratic factors that impact on WBM non (usage) by MSEs in the context of a less technologically advanced society yet one with huge market potentials.

\section{Overview of Related Studies}

Previous studies show that micro, small and medium-scale businesses' use of the World Wide Web in today's fast-changing and highly globalized marketplace could to a great extent serve as an enabler of competitive advantage for these enterprises (Davis \& Vladica, 2006; Lange, 2003; Lewis \& Cockrill, 2002, Poon, 2000), and invariably immensely contribute to their market (or brand) visibility (Handayani \& Lisdianingrum, 2011; Osakwe, Chovancová \& Agu, in press, Worldbank, n.d.). Some studies even posit that the adoption of WBM is a necessity for all growth-aspiring small enterprises, including micro- enterprises that aim to survive their intense business environments (Awiagah, Kang \& Lim, 2015; Lefebvre \& Lefebvre, 2002).

Goodman (2003) examined the benefit which wine industry derives from using the Internet and observed that the internet was heavily under-utilized to capture value for the industry, particularly in the area of revenue generation. On the other hand, his paper indicated that the usage of WBM offers enterprises in the industry a low-cost channel strategy through which these enterprises can stimulate demand for their products, especially when their products can be directly sold to the end-consumers; thereby eliminating disintermediation which could be cost-savings for the firms in the industry. In sum, the author concluded that the usage of the World Wide Web for marketing purposes by small wine industries provides an avenue for these firms to widen their market base and eventually increase their revenue streams.

Similarly, Mathews and Bianchi (2010) observed that the intensity of WBM usage positively correlates with marketing performance of about $96 \%$ of the small Australian firms that were covered in their empirical study. From their study, they concluded that the use of websites, email, online advertising and marketing led to increased sales from new customers in both existing and new 
markets. Since the Internet is one of the most important tools for promoting small, medium and micro enterprises (SMMEs), Govender (2013) tried to ascertain the extent to which the World Wide Web was being used by these SMMEs. It was observed that they were using online directories, social media and e-mails for their promotion mix strategy, but only to a very limited extent.

Notwithstanding the advantages and/or business opportunities that come with the use of WBM, it is evident that due to the inadequacies of most MSEs in developing economies, these enterprises are currently struggling with the initial phase of WBM adoption (Shemi, 2013). Consequently, so many factors are at play regarding MSEs usage of WBM and related technologies (Hairuddina, Noor \& Malik, 2012; Mohamad \& Ismail, 2009; Nejadirani, Behravesh \& Rasoulior, 2011). More specifically, previous studies have shown that aside the financial cost implications of WBM usage, some other vitally important factors that could either inhibit or facilitate the use of WBM among MSEs include the demographic factors of their entrepreneurs (Awa, Emecheta \& Ukoha, 2014; Osakwe, Chovancová \& Agu, in press), socio-cultural with institutional determinism (Awiagah, Kang \& Lim, 2015, Molla \& Licker, 2005a, Salah \& Irwin, 2010), technological issues (e.g., dearth of technical expertise/skills, ease of use, security, perceived risk, etc.) as well as the compatibility of WBM with the already existing workflow (processes) and/or systems in these enterprises (Molla \& Licker, 2005b).

In this study, and as earlier stated, we have chosen to use a decision tree classification technique for our empirical analysis. Decision trees are simply visual models that can be applied in varied situations. In formulating decision trees, various impact related variables are analyzed, using previously built in models that are related with testing data to predict future events (Smith \& Tansley, 2003). Decision trees are used to predict probable outcomes, such as forecasting company's future, customers' intentions and likely decisions (Potter \& Potter, 1988; Fayyad \& Irani, 1992; Hampson \& Volper, 1986).

Decision trees remain one of the main multi-criteria decision analysis tools used in modelling data for decisions. The tool is also used to predict likely decisions and outcomes of certain events using training and testing data (Friedl \& Brodley, 1997). Assumptions are eliminated in decision tree classification, unlike traditional supervised classification processes and are intuitive because of the explicit structure for classification.

Decision tree classification techniques have been applied in various fields. Hampson and Volper (1986) applied decision trees in structuring and training linear function neurons in biology, Friedl and Brodley (1997) used decision trees to classify land cover from remotely sensed data while Hautaniemi et al. (2005) modelled a signal response with decision tree analysis. Tso and Yau (2007) also predicted the consumption of electricity using decision trees while Goodwin, Wrights and Philips (2004) analyzed management judgments using decision tree classification. Similarly, Delina and Tkáč (2010) used decision tree analysis to model trust building mechanisms for electronic business networks and their relations to eSkills in an SME setting.

In addition to the decision tree model, we equally used a multivariate visualization technique, that is, the Andrews' plot. Andrews' curves (plots) are high dimensional data plots that provide a (simultaneous) view of the complex relationships that may exist in a dataset (Andrews, 1972; Spencer, 2003). For detailed information on Andrews' curves, please refer to these studies (Garcia-Osorio \& Fyfe, 2005; Moustafa, 2011; Khattree \& Naikb, 2002; Spencer, 2003). By and large, we strongly believe that using a decision tree classification together with the Andrews' plots will aid us in drawing more robust conclusions from the selected MSEs in our study. Thus, the expected findings will provide some in-depth insights on the (non) usage of WBM by MSEs. 


\section{Methodology}

Structured questionnaires were self- administered to MSEs that indicated interest to participate in the survey. Given the difficulty of obtaining a reliable sampling frame of our target population, we opted to make use of convenience sampling. With the aid of some field assistants, data collection phase was carried out between June, 2014 and October, 2014. The main variables in our research instrument were respondents' gender, academic qualifications, industry type, whether the enterprise is currently using WBM or not, whether the enterprise has the technical/technological expertise to use WBM, access to reliable, relevant and accurate information, and whether WBM is deemed to be necessary for the enterprise marketing activity. Some of the questions were anchored on a 5-point rating scale ranging from strongly disagree to strongly agree. In order to elicit accurate responses from the concerned enterprises in our study, the questionnaires were filled by any one of this set of senior executives - business owners, managing directors, and managers. Hence, MSEs' executives occupying these job positions serve as our key informants in this study. In all, a total number of 267 MSEs situated in the South East Region of Nigeria participated in the study. To ensure that our respondents understood the meaning of web based marketing, we provided a 'clear-cut' definition of the term in the questionnaire. This was done in order to ensure the face validity and to some extent the reliability of the measurement instrument.

In accordance with the World Bank's classification of MSEs, we group MSEs in our study as enterprises employing between one to forty-nine employees.

We used the RapidMiner data mining tool in modelling the decision trees as well as the creation of Andrews' plots. Three decision tree models are presented to identify the key predictor variables that are of concern in taking up WBM by MSEs in Nigeria.

\section{Research Findings and Discussion}

\section{Analysis of Summary Statistics}

A summary of responses from the 267 MSEs from Nigeria is presented in Figure 1. Most of the key respondents in the study were males with the majority having a first degree qualification. Many of the selected MSEs in our study were from the service sector with manufacturing representing the least responses.

The embrace of social media by MSEs in Nigeria appears to be on the increase. Out of the 267 MSEs, 155 have a social media presence while 112 do not have. Revealing in the statistics was that the majority (147) of the MSEs in our study do not use WBM of any form. Although the majority does not use WBM, 243 out of the 267 MSEs accept that WBM is very necessary for the growth of their businesses and equally to gain a competitive edge in the marketplace. The rest of the statistics are depicted in Figure 1. 


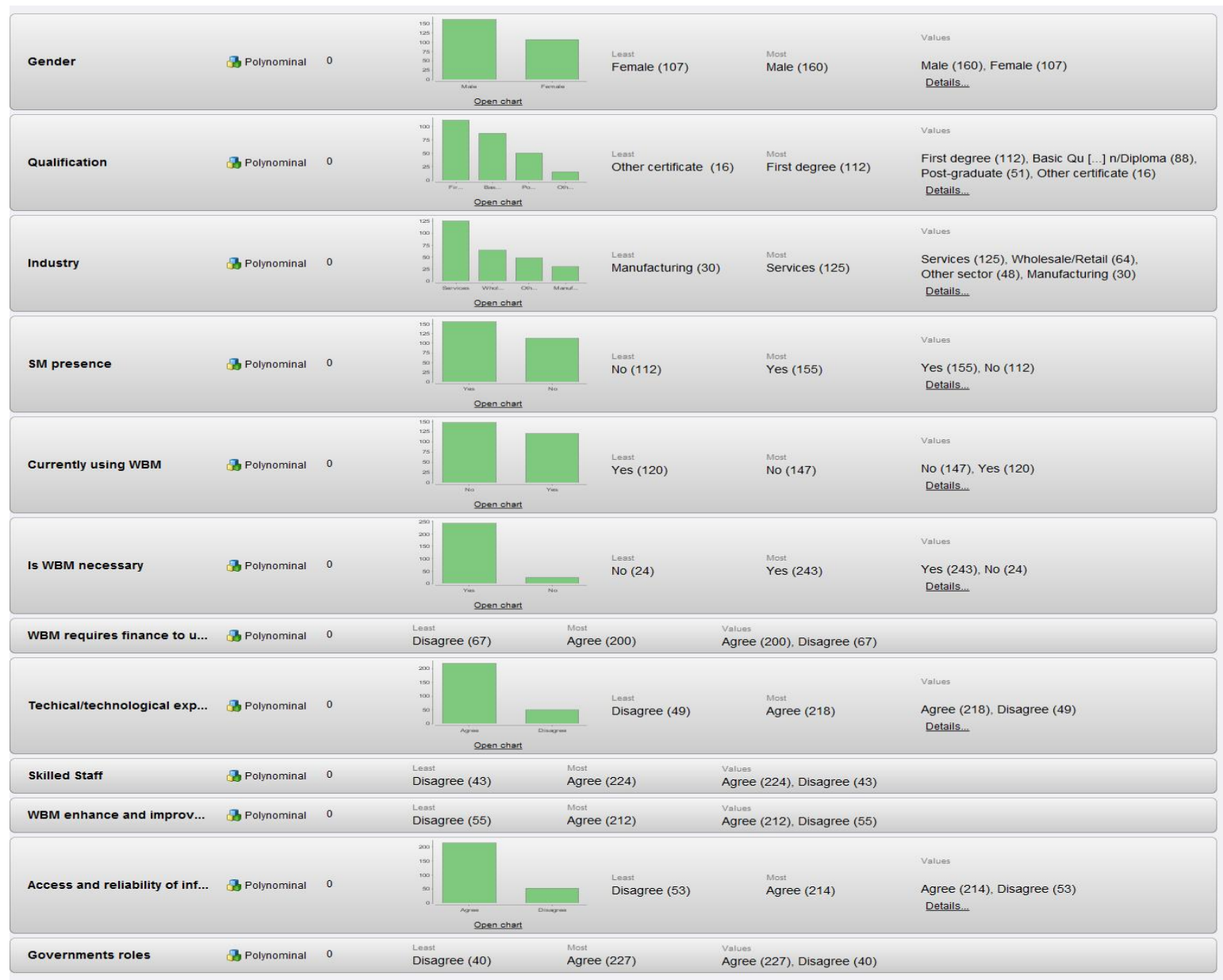

Figure 1: Summary Statistics

\section{Andrews Plot Analysis}

Andrews' curves (plots) are high dimensional data plots (Andrews, 1972) that provide a simultaneous view of all variables used in the analysis. The colours signify, within a scale of alternatives, the alternative that is outstanding in the responses to a particular variable, the flow of responses and display outliers in the data. The Andrews' plots have been used in this paper to classify responses into groups that is convenient for decision tree analysis. In the plot, responses in one group are seen in the same pattern with similar curves. The curving nature of the plots depicts similar responses in different patterns.

In Figure 2, an Andrews plot is created for responses on the variable Is WBM necessary for their enterprise activities? The majority of respondents with a code of 2 for Yes, agree that WBM is very important. Not so surprisingly, some respondents do not agree that WBM is necessary while the lower part of the plot signifies that WBM may even be necessary for the few enterprises that felt otherwise. Perhaps, for these enterprises, it is suggestive to say that WBM might not be compatible with their current business modus operandi, so they might even become resistant to the idea of using WBM as part of their business operations. 


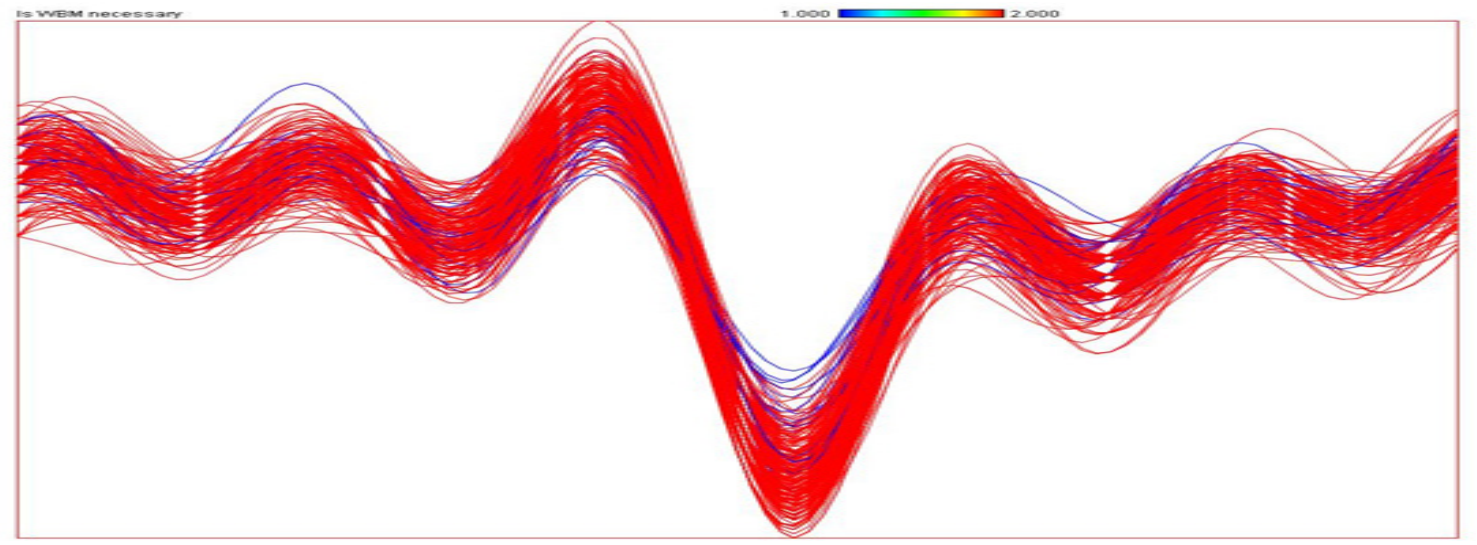

Figure 2: Is WBM necessary? (Coding 1 = No- Blue Colour; 2 = Yes- Red Colour)

As indicated in the summary statistics, the Andrews' plot confirms that most of the MSEs are currently not using WBM. As seen in Figure 3, with code 1 representing No and 2 representing Yes, more respondents signify that WBM is currently not being deployed in their enterprises. It could be visualized that spotted respondents agree that their enterprises use WBM.

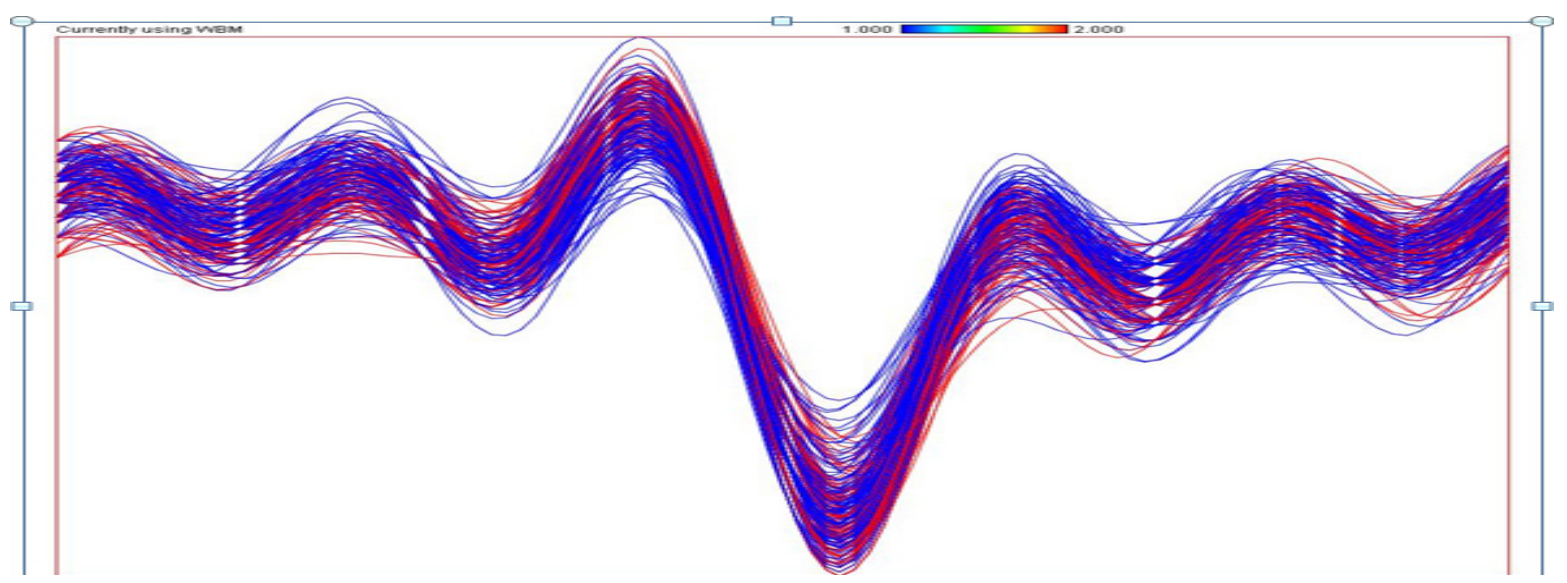

Figure 3: Currently using WBM (Coding 1 = No- Blue Colour; 2 = Yes- Red Colour)

As shown in Figure 4, social media presence responses are pictorially analyzed in the Andrews plot. There is a close relation between the responses of Yes and No in the plot. The plot appears to signify that an equal proportion of MSEs either currently make use of social media or do not have any form of social media presence.

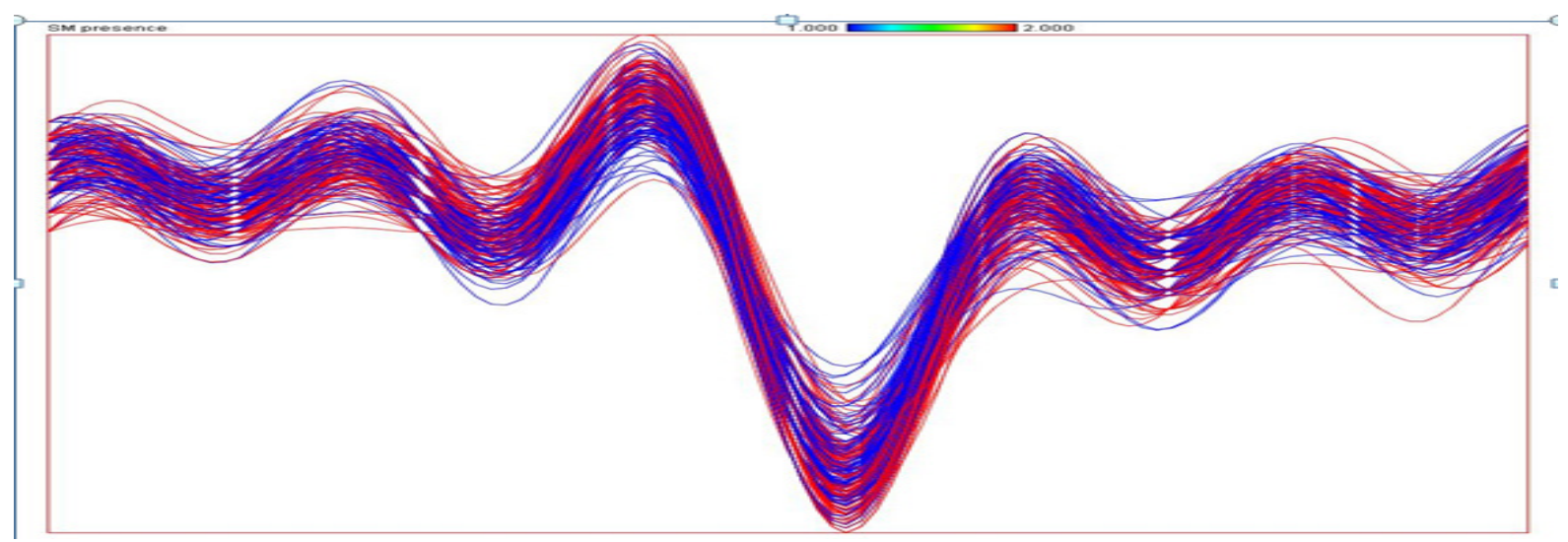

Figure 4: Social Media Presence (Coding 1 = No- Blue Colour; 2 = Yes- Red Colour) 


\section{Decision Tree Model Analysis}

The decision tree classification was applied on three separate bases. The study sought to find out the best predictor variables in considering whether WBM is necessary, whether the company is currently using WBM and whether technical/technological expertise is key in WBM. The three decision tree classifications for the label variables of the models are presented and analyzed below.

In Figure 5, the tree sought to create a model that will predict the responses from respondents, whether WBM is necessary for their enterprise activities? The tree indicates that social media presence is the best predictor for the label variable (whether WBM is necessary?). When the response to social media presence is $N o$, the next predictor variable is to determine the particular industry the MSE belongs to. When the industry is Services, the next predictor variable is to identify the academic qualification of the respondents in their enterprises. Furthermore, gender appears to serve as a good predictor variable most especially as it applies to the post-graduate qualification of the respondents in the study. The result is suggestive that the more educated women folks in the service industry are highly likely to use leverage on the power of the social media for promoting and/or marketing their service offering. This particular finding is in line with a recent study on the increasing usage of social media usage among women entrepreneurs (Ukpere, Slabbert \& Ukpere, 2014).

On one hand, when the response to social media presence is Yes, the next variable of interest is yet academic qualifications. It is interesting to note that respondents with basic, first degree and postgraduate academic qualifications all appear to agree that WBM is relevant (necessary) as long as an enterprise has a social media presence. On the contrary, when an enterprise does not have a social media presence, key informants with basic and first degree holders seem to indicate that WBM is not a necessity. The full tree description is as shown in Appendix A. Thus, the findings suggest that firms with a social media presence are more likely to perceive WBM as one of the relevant channels they could use to market their products. This finding provides support for prior studies on the impacts of online social networking platforms in the context of entrepreneurial marketing (e.g., Indrupati \& Henari, 2012).

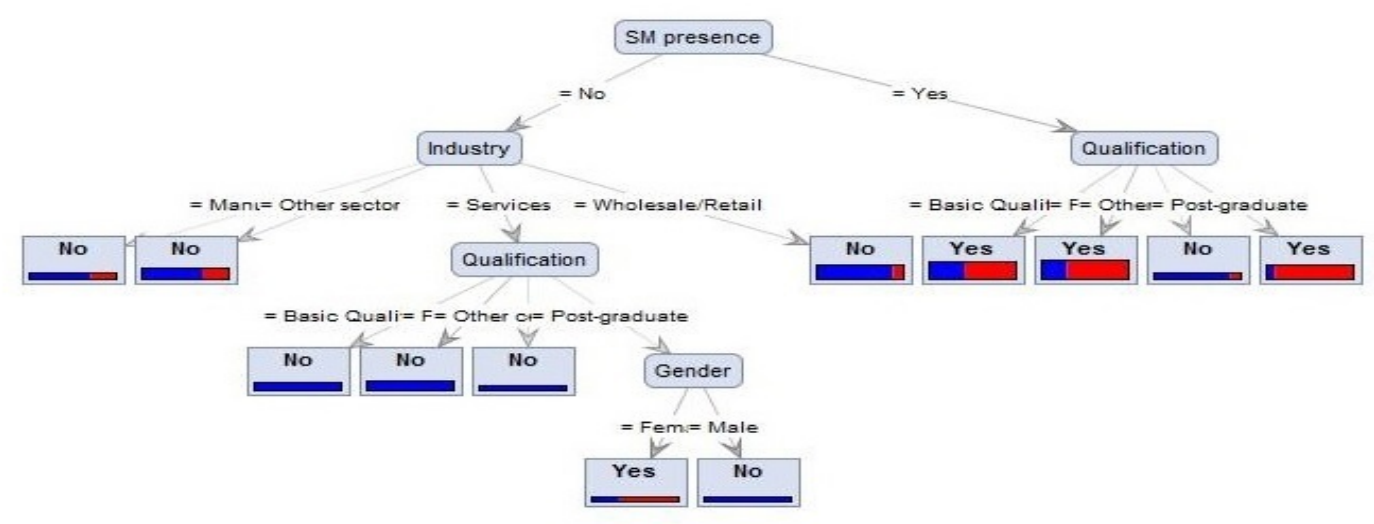

Figure 5: Decision tree model for whether WBM is relevant (necessary) to an enterprise

The best predictor variable to predict whether access to reliable, relevant, timely and accurate information is the bane in the usage of WBM by the selected MSEs in Nigeria is whether WBM enhances and improves business (see Figure 6).

If the response to the best predictor value is Agree, then aggregately, the prediction is that access to reliable, relevant, timely and accurate information is key to the usage of WBM. If the response 
is Disagree, the next predictor variable to investigate is the response to whether WBM requires slack financial resources to be able to use and maintain it. As seen in Figure 6, the Disagree response further allows the investigation of government facilitating roles as the next best predictor variable. When the response to government roles is Disagree, then there is an outright disagreement that access to reliable, relevant, timely and accurate information is key to WBM usage by MSEs.

However, if the response to government roles is Agree, then social media presence as the next predictor variable is investigated. With a Yes response to social media presence, the response to access to reliable, relevant, timely and accurate information is in the affirmative, while a No response gives a negative prediction to the label variable. Kindly refer to Appendix B for the tree description of Figure 6.

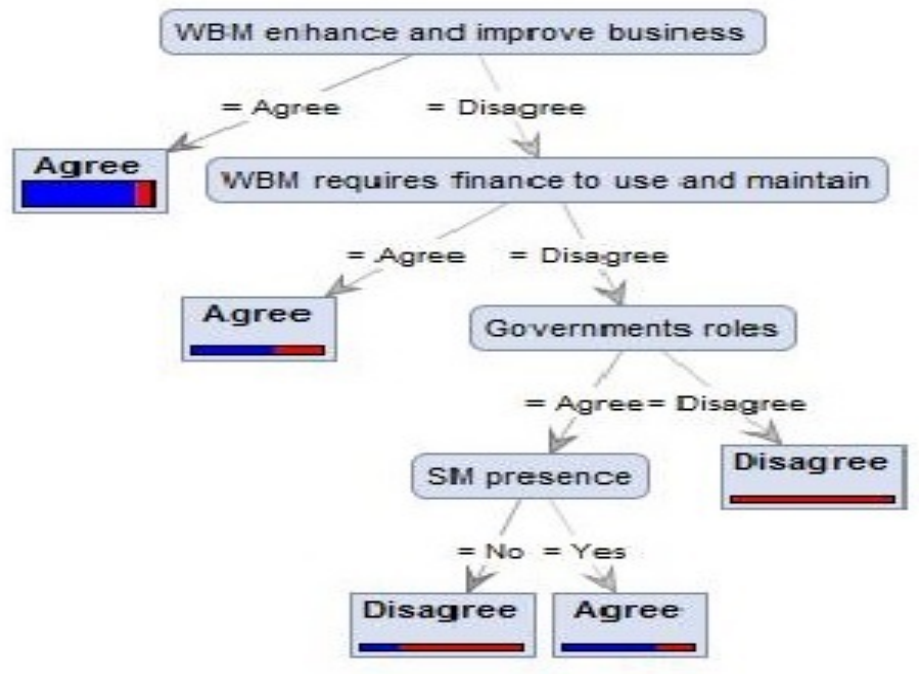

Figure 6: Decision tree model to predict whether an enterprise is currently using WBM

To predict whether technical/technological expertise is key in WBM by MSEs in Nigeria, the best predictor variable to consider is the response to the requirement of financial support to use and maintain WBM. The response to this predictor variable leads to a host of a lineage of other variables, whether the response is Agree or Disagree as shown in Figure 7. It could be observed (see Figure 7) that variables such as skilled staff and whether WBM enhances and improves business, feature prominently in the two branches of the tree.

Furthermore, when the response to the best predictor variable as shown in Figure 7 is Disagree, the response to the next predictor variable (WBM enhance and improve business) is Dsagree, a Yes response to the next predictor variable (currently using WBM), then there is an outright prediction of technical and technological expertise not being necessary for undertaking WBM in the context of MSEs in Nigeria.

However, if the response to the predictor variable (currently using WBM) is No, the response to the next predictor variable (Need for skilled staff in WBM), is further examined. Kindly refer to Figure 7 for further details of the final prediction to the label variable of the necessity of technical/ technological expertise in WBM. See also Appendix C for The full tree description of Figure 7. In sum, the findings show that financial and technological resources play instrumental roles in either the decision to use and/or consideration of the relevance of WBM to meeting the need of an enterprise. These findings provide further support for previous studies (e.g., Molla \& Licker, 2005a, 2005b; Nejadirani et al., 2011). 


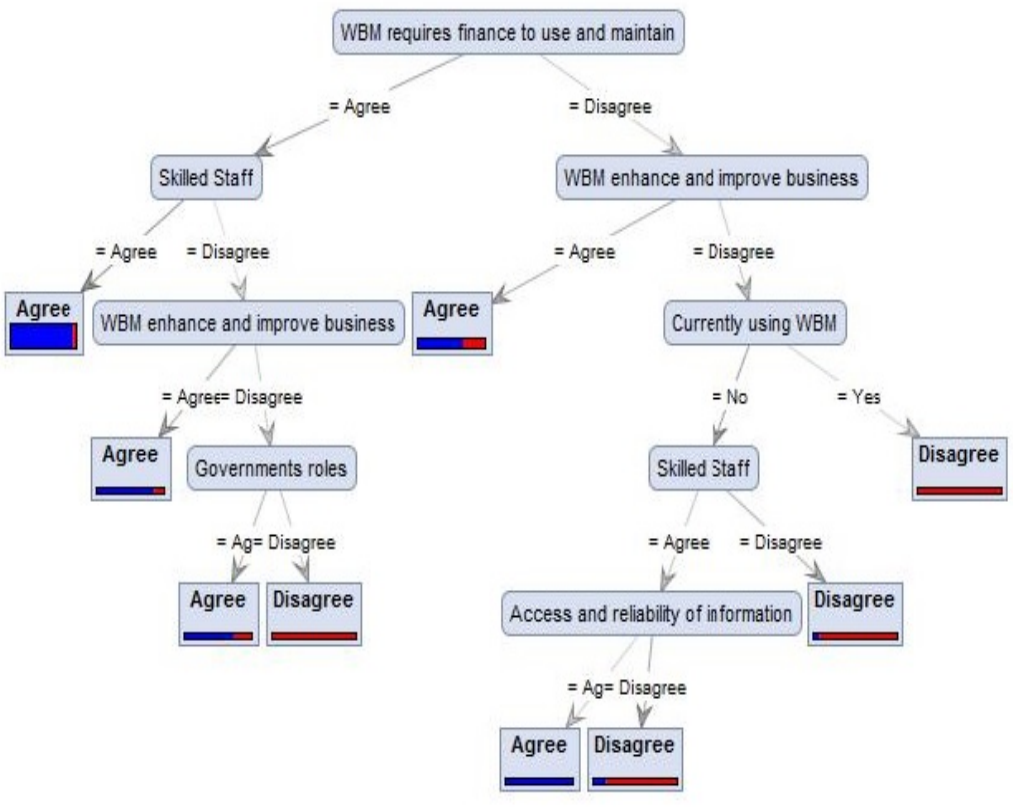

Figure 7: Decision tree model to predict the necessity of technical/technological expertise for WBM

\section{Summary and Concluding Thoughts}

In this paper, an attempt has been made to identify relevant predictor variables for web based marketing usage in the context of MSEs situated in one of Africa's largest economies. Based on our findings from the three decision tree classifications (see Figures 5, 6 and 7 respectively), key variables that appeared to be salient in enterprises undertaking WBM in Nigeria are social media presence, the role of government in enhancing WBM, and the knowledge coupled with an understanding of whether WBM enhances business performance or not. These variables are grounded, from the decision tree classifications above, in enterprises currently using or predicted to use WBM for competitive advantage.

One of the novel findings in this study appears to show that service-oriented enterprises with a social media presence and that are equally headed by highly educated females are more likely to use online social media (e.g., Facebook, Twitter, Linkedln, Instagram, etc.) to market their professional services. Hence, this goes to show that the highly educated female business owners (and/or senior managers) may perceive social media as not only a social interaction platform, but also as a strong and compelling market platform for an enterprise to enrich its customer-base and/or enhance its brand image in the marketplace.

A majority of the enterprises irrespective of their industry types concur that WBM is relevant to their marketing activities given that it has the potential of enhancing their business performance. Notwithstanding, a majority of these enterprises are yet to implement WBM as reflected in Figure 1. It is also stated that MSEs that are willing to commit their financial resources to the usage of WBM as well as enterprises with skilled management staff are more than likely to perceive WBM as a competitive marketing intelligence tool.

We suggest that policy makers in Nigeria should come up with solutions that can make Internet services much more affordable and reliable as well as the provision of regular power supply. This 
would go a long way in supporting enterprises with the ambition of leveraging on the World Wide Web for both marketing and non-marketing activities.

The role of the government of Nigeria as well as other developing countries cannot be underscored given that the government must be seen as one of the key drivers of the Internet economy. The authors strongly believe that the fundamental role of government as an enabler of the Internet marketplace is strongly linked to the growth of web based marketing adoption by enterprises in the global economy. Moreover, for MSEs in Nigeria to actualize their growth potentials and become 'regionally' competitive in the African business landscape, leveraging on WBM must be seen as a necessity.

Lastly, we acknowledge the fact that our sample size may be relatively small; consequently we were unable to split our dataset into training data and validation data. Nonetheless, since this is an exploratory study, our findings provide room for further research. Future studies should explore the marketing factors and/or strategic orientations that can contribute to the usage of WBM by MSEs in the developing world, especially those in the African continent. On the whole, we believe that the results of this study to an extent reflect a holistic view of some of the likely key variables that are influencing the (non) usage of WBM among MSEs in Nigeria. To conclude, this paper has provided further insights on some of the relevant predictor variables of web based marketing (non) usage by MSEs in Nigeria. The findings of this study may as well be applicable to similar developing countries

\section{Acknowledgement}

This research paper is supported in part by the UTB in Zlin Internal Grant Agency Project (IGA/FaME/2014/007) / (IGA/FaME/2015/039).

\section{References}

Abouzeedan, A., Klofsten, M., \& Hedner, T. (2013). Internetization management as a facilitator for managing innovation in high-technology smaller firms. Global Business Review, 14(1), 121-136.

Andrews, D. F. (1972). Plots of high-dimensional data. Biometrics, 28(1), 125-136.

Awa, H. O., Emecheta, B. C., \& Ukoha, O. (2014). Location factors as moderators between some critical demographic characteristics and ICT adoption: A study of SMEs. Proceedings of Informing Science \& IT Education Conference (InSITE) (pp. 39-52). Retrieved February 24, 2015 from http://Proceedings.InformingScience.org/InSITE2014/InSITE14p039-052Awa0542.pdf

Bengtsson, M., Boter, H., \& Vanyushyn, V. (2007). Integrating the internet and marketing operations: A study of antecedents in firms of different size. International Small Business Journal, 25(1), 27-48.

Centeno, V. P. (2001). The role of the micro enterprises as engine of economic development: The Peruvian case. Paper Presentation at the IFUP 4th International Conference (October 16-19th), Marrakesh, Morocco. Retrieved November 21, 2014 from http://ww2.unhabitat.org/programmes/ifup/conf/Summary.PDF

Chen, X. (2009). A comparison of decision tree and logistic regression mode (Paper D02). SAS Conference Proceedings: Midwest SAS Users Group, October 11-13, Cleveland, Ohio, USA. Retrieved 25 February, 2015 from http://www.mwsug.org/proceedings/2009/stats/MWSUG-2009-D02.pdf

Coad, A., \& Tamvada J. P. (2008). The growth and decline of small firms in developing countries. Papers on Economics \& Evolution, Paper \#0808, Max Planck Institute of Economics, Evolutionary Economics Group. Retrieved November 21, 2014 from http://www.econ.mpg.de/files/papers/evo/discussionpapers/2008-08.pdf

Daniels, L. (1999). The role of small enterprises in the household and national economy in Kenya: A significant contribution or a last resort? World Development, 27(1), 55-65. 
Davis, C.H. \& Vladica, F. (2006). Use of internet technologies and e-business solutions: A structural model of sources of business value among Canadian micro-enterprises. In: Proceedings of the 39th Annual Hawaii International Conference on System Sciences (HICSS) (Volume:8, pp 1-10), 4-7 January. Retrieved February 24, 2015 from http://dx.doi.org/10.1109/HICSS.2006.519

Delina, R. \& Tkáč, M. (2010). Trust building mechanisms for electronic business networks and their relation to eSkills. International Scholarly and Scientific Research \& Innovation, 4(10), 325-335.

Eshetu, T., Ketema, T., \& Kassa, B. (2013). Economic impact of support service program on micro and small enterprises: The case of Dire Dawa Administration, Ethiopia. Agris on-line Papers in Economics and Informatics, 5(1), 21-29.

Etemad, H., Wilkinson, I., \& Dana, L. P. (2010). Internetization as the necessary condition for internationalization in the newly emerging economy. $J$ Int Entrep, 8, 319-342.

Fajnzylber, P., Maloney, W. F., \& Montes-Rojas, G.V. (2009). Releasing constraints to growth or pushing on a string? Policies and performance of Mexican micro-firms. Journal of Development Studies, 45(7), 1027-1047.

Fayyad, U. M., \& Irani, K. B. (1992). On the handling of continuous-valued attributes in decision tree generation. Machine learning, 8(1), 87-102.

Friedl, M. A., \& Brodley, C. E. (1997). Decision tree classification of land cover from remotely sensed data. Remote sensing of environment, 61(3), 399-409.

Garcia-Osorio, C. \& Fyfe, C. (2005). Visualization of high-dimensional data via orthogonal curves. Journal of Universal Computer Science, 11(11):1806-1819.

Goodman, S. (2003). A framework for the implementation of (internet) marketing by the wine business. International Wine Marketing Symposium Proceeding, Adelaide, Australia, 26-27 July.

Goodwin, P., Wright, G., \& Phillips, L. D. (2004). Decision analysis for management judgment (p. 270) London: Wiley.

Govender, J. P. (2013) Using the Internet to market small, medium and micro enterprises in a developing economy. Problems and Perspectives in Management, 11(4): 20-27.

Hampel-Milagrosa, A., Loewe, M., \& Reeg, C. (2015). The entrepreneur makes a difference: Evidence on MSE upgrading factors from Egypt, India, and the Philippines. World Development, 66, 118-130. Retrieved November 22, 2014 from http://dx.doi.org/10.1016/j.worlddev.2014.08.005

Hampson, S. E., \& Volper, D. J. (1986). Linear function neurons: Structure and training. Biological Cybernetics, 53(4), 203-217.

Hairuddin, H., Noor, N.L. Md \& Malik, A. Md. Ab. (2012). Why do microenterprise refuse to use information technology: A case of batik microenterprises in Malaysia. Procedia - Social and Behavioral Sciences, 57, 494 - 502. (International Conference on Asia Pacific Business Innovation and Technology Management).

Handayani, P. W. \& Lisdianingrum, W. (2011). Impact analysis on free online marketing using social network facebook: Case study SMEs in Indonesia. In International Conference on Advanced Computer Science and Information Systems (ICACSIS), 17-18 December, Jakarta, p. 171-176. Retrieved February 24, 2015 from http://ieeexplore.ieee.org/stamp/stamp.jsp?tp=\&arnumber=6140803\&tag=1

Hautaniemi, S., Kharait, S., Iwabu, A., Wells, A., \& Lauffenburger, D. A. (2005). Modeling of signalresponse cascades using decision tree analysis. Bioinformatics, 21(9), 2027-2035.

Indrupati, J., \& Henari, T. (2012). Entrepreneurial success, using online social networking: Evaluation. Education, Business and Society: Contemporary Middle Eastern, 5(1): 47 - 62.

Khattree, R. \& Naikb, D. N. (2002). Andrews plots for multivariate data: Some new suggestions and applications. Journal of Statistical Planning and Inference, 100(2): 411-425. 
Lange, C. (2003). Developing strategies for electronic commerce in small and medium sized companies Guidelines for managers. Arbeitsberichte des Instituts für Wirtschafts- und Verwaltungsinformatik, Universit"at Koblenz-Landau, No. 39. Retrieved February 24, 2015 from http://www.wi-inf.uniduisburg-essen.de/FGFrank/documents/Arbeitsberichte_Koblenz/Nr39.pdf

Lefebvre, L. A., \& Lefebvre, E. (2002). E-commerce and virtual enterprises: Issues and challenges for transition economies. Technovation, 22, 313-323.

Lewisa, R. \& Cockrill, A. (2002). Going global—remaining local: The impact of e-commerce on small retail firms in Wales. International Journal of Information Management, 22, 195-209.

Liedholm, C. (2002). Small firm dynamics: Evidence from Africa and Latin America. Small Business Economics, 18, 227-242.

Mathews, S., \& Bianchi, C. (2010). Internet usage, internet marketing intensity and international marketing growth. In Proceedings of the Global Marketing Conference: Marketing in a Turbulent Environment, 10-12 September, Tokyo, Japan. Retrieved 17-02-2015 from http://eprints.qut.edu.au/39233/1/c39233.pdf

McPherson, M. A. (1996). Growth of micro and small enterprises in southern Africa. Journal of Development Economics, 48, 253-277.

Mead, D. C., \& Liedholm, C. (1998). The dynamics of micro and small enterprises in developing countries. World Development, 26(1), 61-74.

Mohamad, R., \& Ismail, N. A. (2009). Electronic commerce adoption in SME: The trend of prior studies. Journal of Internet Banking and Commerce, 14(2), 1-16.

Molla, A \& Licker, P. (2005a). Perceived e-readiness factors in e-commerce adoption: An empirical investigation in a developing country. International Journal of Electronic Commerce, 10(1): 83-110.

Molla, A., \& Licker, P.S. (2005b). E-Commerce adoption in developing countries: A model and instrument. Information \& Management, 42, 877-899.

Moustafa R. E. (2011). Andrews curves. Wiley Interdisciplinary Reviews: Computational Statistics (WIREs Computational Statistics), 3(4), 373-382. doi: 10.1002/wics.160

Nejadirani, F., Behravesh, M. \& Rasouli, R. (2011). Developing countries and electronic commerce: The case of SMEs. World Applied Sciences Journal, 15(5), 756-764.

Nichter, S., \& Goldmark, L. (2009). Small firm growth in developing countries. World Development, 37(9), $1453-1464$.

Osakwe, C. N., Chovancová, M. \& Agu, M. (in press). Can micro- enterprises leverage on the adoption of corporate website to bolster their brand visibility? Examining salient adoption issues in a developing country context. Information Development.

Poon, S. (2000). Business environment and Internet commerce benefits -A small business perspective. European Journal of Information Systems, 9, 72-81.

Potter, B., \& Potter, M. C. (1988). U.S. Patent No. 4,733,354. Washington, DC: U.S. Patent and Trademark Office.

Salah, K. \& Irwin, B. (2010). A structurational view of e-commerce in SMEs in least developing countries (pp. 1-12). 18th European Conference on Information Systems, 7 - 9 June, Pretoria, South Africa. Retrieved February 25, 2015 from http://is2.lse.ac.uk/asp/aspecis/20100076.pdf

SAS Support (n.d.). Decision trees- What are they? Retrieved February 25, 2015 from http://support.sas.com/publishing/pubcat/chaps/57587.pdf

Shemi, A. P. (2012). Factors affecting e-commerce adoption in small and medium enterprises: An interpretive study of Botswana. PhD Thesis, Salford Business School, University of Salford, UK. Retrieved February 24, 2015 from http://core.ac.uk/download/pdf/9842780.pdf

Smith, L., \& Tansley, J. (2003). Decision tree analysis. United States Patent Application 2004019948. 
Spencer, N. H. (2003). Investigating data with Andrews Plots. Social Science Computer Review, 21(2), 244-249. Retrieved from http://dx.doi.org/10.1177/0894439303021002010

Quinlan, J. R. (1987). Simplifying decision trees. International Journal of Man-Machine Studies, 27(3), 221-234.

Tornatzky, L., \& Fleischer, M. (1990). The processes of technology innovation. Lexington, MA: Lexington Books.

Trainor, K.J., Rapp, A., Beitelspacher, L.S., \& Schillewaert, N. (2011). Integrating information technology and marketing: An examination of the drivers and outcomes of e-Marketing capability. Industrial Marketing Management, 40(1), 162-174.

Tsiotsou, R. H., \& Vlachopoulou, M. (2011). Understanding the effects of market orientation and emarketing on service performance. Market Intelligence \& Planning, 29(2), 141-155.

Tso, G. K., \& Yau, K. K. (2007). Predicting electricity energy consumption: A comparison of regression analysis, decision tree and neural networks. Energy, 32(9), 1761-1768.

Ukpere, C. L., Slabbert, A. D., \& Ukpere, W.I. (2014). Rising trend in social media usage by women entrepreneurs across the globe to unlock their potentials for business success. Mediterranean Journal of Social Sciences, 5(10), 551-559.

Varadarajan, P. R., \& Yadav, M. S. (2002). Marketing strategy and the internet: An organizing framework. Academy of Marketing Science Journal, 30(4), 296-312.

Woldeyohanes, H. T. (2014). Dimensions and determinants of growth in micro and small enterprises: Empirical evidence from Mekelle City, Ethiopia. Agris on-line Papers in Economics and Informatics, 6(3), 104-115.

Worldbank. (n.d.). E-business adoption by micro and small enterprises: Comparative analysis of eleadership strategies. Retrieved February 24, 2015 from http://web.worldbank.org/archive/website00894A/WEB/PDF/COMPARAT.PDF

\section{Appendix A \\ Decision Tree Model Description For Whether WBM is Necessary to an Enterprise Tree 1 Description of Figure 5}

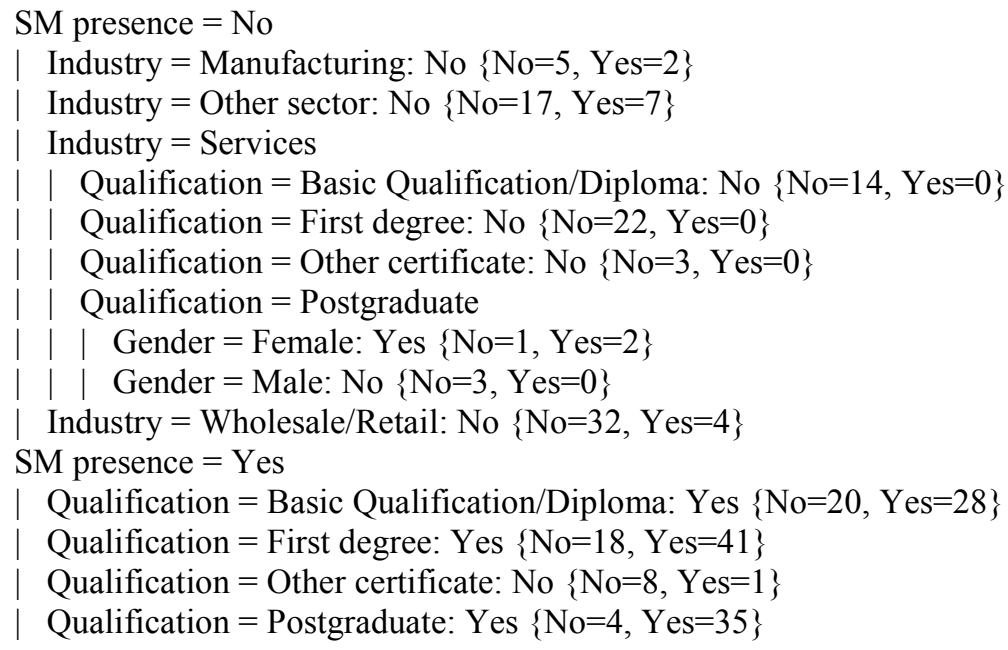




\section{Appendix B}

\section{Decision tree model Description to Predict Whether an Enterprise is Currently Using WBM Tree 2 Description of Figure 6}

WBM enhance and improve business $=$ Agree: Agree $\{$ Agree $=189$, Disagree $=23\}$

WBM enhance and improve business $=$ Disagree

WBM requires finance to use and maintain $=$ Agree: Agree $\{$ Agree $=19$, Disagree $=10\}$

WBM requires finance to use and maintain $=$ Disagree

Governments roles $=$ Agree

SM presence $=$ No: Disagree $\{$ Agree $=3$, Disagree $=9\}$

| $\mathrm{SM}$ presence $=$ Yes: Agree $\{$ Agree $=3$, Disagree $=1\}$

Governments roles $=$ Disagree: Disagree $\{$ Agree $=0$, Disagree $=10\}$

\section{Appendix C}

Decision tree model Description to Predict the Necessity of Technical/Technological Expertise for WBM

Tree 3 Description of Figure 7

$\mathrm{WBM}$ requires finance to use and maintain $=$ Agree

Skilled Staff $=$ Agree: Agree $\{$ Agree $=170$, Disagree $=8\}$

Skilled Staff $=$ Disagree

| WBM enhance and improve business $=$ Agree: Agree $\{$ Agree $=13$, Disagree $=2\}$

WBM enhance and improve business $=$ Disagree

| | Governments roles $=$ Agree: Agree $\{$ Agree $=3$, Disagree $=1\}$

| | | Governments roles $=$ Disagree: Disagree $\{$ Agree $=0$, Disagree $=3\}$

WBM requires finance to use and maintain $=$ Disagree

WBM enhance and improve business $=$ Agree: Agree $\{$ Agree $=28$, Disagree $=13\}$

WBM enhance and improve business $=$ Disagree

Currently using WBM = No

Skilled Staff $=$ Agree

Access and reliability of information $=$ Agree: Agree $\{$ Agree $=2$, Disagree $=0\}$

Access and reliability of information $=$ Disagree: Disagree $\{$ Agree $=1$, Disagree $=5\}$

Skilled Staff $=$ Disagree: Disagree $\{$ Agree $=1$, Disagree $=11\}$

Currently using WBM $=$ Yes: Disagree $\{$ Agree $=0$, Disagree $=6\}$

\section{Biographies}

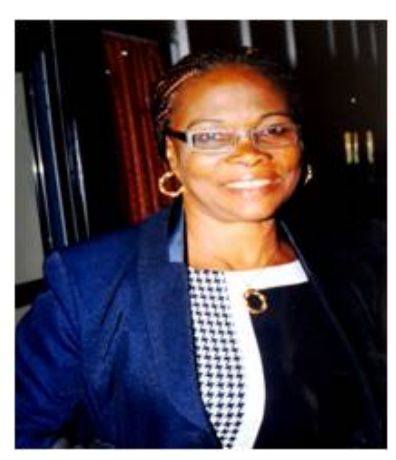

Dr(Mrs) Monica N. Agu is a Senior Lecturer at the Department of Computer Science, University of Nigeria, Nsukka. She obtained a BSC Computer Science at the University of Ibadan in 1978, Master of Science Degree in Computer Science at the University of Nigeria, Nsukka in 1995 and PhD Degree in Computer Science from Ebonyi State University, Abakaliki in 2009. Her research has focused on using Information and Communication Technology to improve the lives of people and Modelling performance of Computer Systems. She has several publications in both local and international journals. 


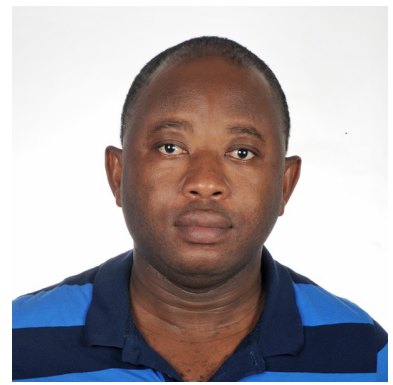

Mr. Stephen Nabareseh is a PhD candidate in Economics and Management. The author specializes in data mining, decision sciences, Management science and Operations research. The author teaches decision making under risk and uncertainty as a course at the Tomas Bata University in Zlin. Mr. Nabareseh has also tutored students in Marketing Research as a seminar course at the same University. He has to his credit scholarly articles indexed in reputable academic databases.

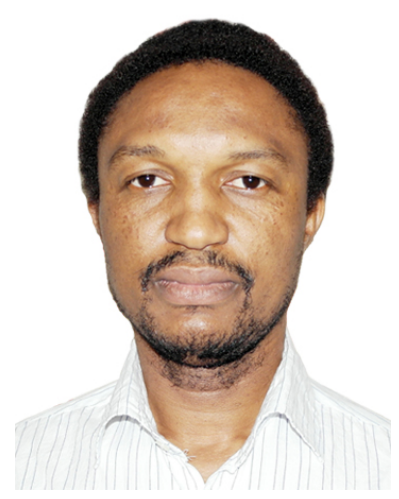

Christian Nedu Osakwe is a $\mathrm{PhD}$ Candidate of Management and Economics at the Faculty of Management and Economics, Tomas Bata University in Zlin, Czech Republic. He is equally a Seminar Lecturer of Applied Marketing Research, Principles of Marketing, and Brand Management at his university. His research interests are but not limited to, research methods, strategic marketing, technology adoption/diffusion, micro, small and medium-sized enterprises (MSMEs) and consumer behaviour. He has some academic publications to his credit. 